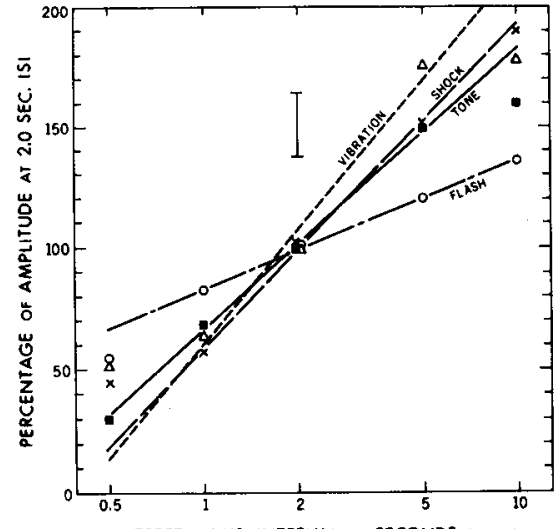

INTERSTIMULUS INTERVAL IN SECONDS (LOG.)

Fig. 2. Recovery functions for four types of stimulation: average of medians for four Ss. The medians for each $S$ were first normalized, with the amplitude (for the appropriate, stimulus) at 2.0-sec ISI taken as $100 \%$. The normalized medians were then averaged across Ss. A straight line for each type of stimulus was fitted by eye to the points for the 1-, 2-, and 5-sec interstimulus intervals. The interquartile range of the normalized amplitudes at 2-sec ISI $(N=16)$ is shown by the vertical bar above the cluster of points. The data are too scanty for meaningful measures of dispersion at the other points, but the range of amplitudes is particularly large for the responses to shock and to vibration at 10-sec ISI.

taking as $100 \%$ his median response for each stimulus at the $2.0-\mathrm{sec}$ interstimulus interval. The median values were then averaged across Ss. Figure 2 displays these average amplitudes for each type of stimulus. Straight lines were fitted by eye to the points at 1.0-, 2.0-, and 5.0-sec ISI for each type of stimulus. Note that the points for the 10.0-sec ISI fall on the appropriate straight lines for flashes and for shocks but below the lines for tones and vibrations. The responses at $0.5-\mathrm{sec}$ ISI were small for all types of stimuli and were frequently distorted or completely obscured by the background noise.

The slopes of the recovery functions plotted in Fig. 2 are conveniently expressed as the percentage increase in amplitude of $\mathrm{N}_{1} \cdot \mathrm{P}_{2}$ produced by doubling the interstimulus interval within the range from 1 to $5 \mathrm{sec}$. The increases are, for vibration, $48 \%$; for shocks, $41 \%$; for tones, $35 \%$; for flashes, $16 \%$. The recovery function for flashes has much the flattest slope of the four.

CONCLUSIONS AND DISCUSSION

The amplitudes of the responses to all four types of stimuli conform to a linear function fitted to the three middle interstimulus intervals $(1.0,2.0$, and
$5.0 \mathrm{sec}$ ) when amplitude is plotted against the logarithm of the ISI. The recovery functions level off between 5.0 and $10.0 \mathrm{sec}$ for tones and vibration. Nelson \& Lassman's data (1968) indicated such a leveling off for tones. Our points at the 10.0-sec ISI still fall on the straight line for both flashes and shocks. Actually the $10.0-\mathrm{sec}$ ISI point for shock is relatively high in the averaged data because of one $S$ who had an extremely high-amplitude response at that interval. The data from the other three Ss showed a leveling off at $5.0-\mathrm{sec}$ ISI for shocks. Thus the shock, vibrotactile, and auditory modalities have recovery functions that are similar in slope and also in the ISI at which they "level off," while the visual recovery function is clearly different.

No single $S$ 's data could be fitted satisfactorily with a straight line for each modality. One S's recovery function for vision and another's for shock leveled off as early as $2.0 \mathrm{sec}$. These deviations seem to be random and may or may not be characteristic of the individual. The suggestion of Rothman, Davis, \& Hay ${ }^{4}$ that a more rapid recovery may follow shocks than tones was confirmed for only one of the four Ss. We interpret their results as due to variability or individual differences, or both.

\section{REFERENCES}

DAVIS, H., MAST, T., YOSHIE, N., \& ZERLIN, $S$. The slow response of the human cortex to auditory stimuli: Recovery process. Electroencephalography \& Clinical Neurophysiology, 1966, 21, 105-133.

HAY, I. S. The slow cortical evoked potential: Cross-modality interaction of auditory, vibro-tactile and shock stimuli. Unpublished MA thesis, Washington University, January 1970.

NELSON, D. A., \& LASSMAN, F. M. Effects of intersignal interval on the human auditory evoked potential. Journal of the Acoustical Society of America, 1968, 44, 1529-1532.

ROTHMAN, H. H., \& DAVIS, H. The amplitude of slow evoked cortical responses in relation to temporal features of stimulation. Electroencephalography \& Clinical Neurophysiology, 1969, 27, 699-700. NOTES

1. This investigation was supported by Public Health Service Grant NB-03856 from the National Institute of Neurological Diseases and Stroke.

2. The authors thank Dr. Hallowell Davis for the suggestion of the problem and for his guidance in the conduct of the experiments and in preparation of the manuscript.

3. Present address: Department of Psychology, Florida State University, Tallahassee, Fla. 32306.

4. Rothman, H. H., Davis, H., \& Hay, I. S. Slow evoked cortical potentials: Interactions of electrical and auditory stimuli. In preparation.

\title{
The effects of delayed judgmental similarity on evaluative attraction
}

GUILLERMO F. MASCARO, University of effects of similarity on attraction and on Florida, Gainesville, Fla. 32601, and JOSE evaluations of intelligence and knowledge A. LOPEZ, Embry-Riddle Aeronautical were found. However, the effects of Institute, Municipal Airport, Datona Beach, judgmental similarity on evaluations of Fla. 32015 The effects of three levels of judgmental similarity (i.e., conceptualized as cognitive similarity on evaluation and attraction attitudinal component) on evaluative were investigated under noninteraction attraction with the effects of similarity in delayed-feedback conditions. Significant the evaluative attitude dimension. 
Reviews of the literature reveal that, under a variety of conditions (e.g., field experiments, laboratory interaction, hypothetical situations, etc.), interpersonal attraction has been found to be functionally related to similarity of attitudes (Berscheid \& Walster, 1969; Byrne, 1969). In a recent investigation, Mascaro (1970) extended the generality of the similarity-attraction relationship by demonstrating that judgmental similarity increased evaluative attraction using a situation of laboratory interaction in which a $S$ and a confederate received immediate feedback on their simultaneous answers to a series of quantity-estimation questions. In order to establish the generality of effects of judgmental similarity beyond interaction or immediate-feedback situations (which enhance the similarity-dissimilarity of responses), an investigation was conducted testing the effects of judgmental similarity on attraction under noninteraction delayed-feedback conditions.

\section{METHOD}

Fifty-three male students from Embry-Riddle Aeronautical Institute were a dministered an information questionnaire $^{1}$ consisting of 20 binary multiple-choice questions, i.e., error-choice-type items (Hammond, 1948), on different social issues. A week later, the Ss were falsely informed that the information questionnaire had been given as part of a study in interpersonal prediction. They were told that other students had answered the same questionnaire and that they were to be given each other's tests (with names removed) in order to determine how much they could learn from one another from this information alone. Each $S$ received a questionnaire answered by another student and was asked to rate that student on an Interpersonal Judgment Scale (Byme, 1961). The Interpersonal Judgment Scale (IJS) consists of six 7-point rating scales on a person's intelligence, knowledge of attitudes (e.g., Byme, 1969). It should be current events, morality and adjustment, pointed out, however, that the theoretical

Table 1

Means, Standard Deviations, and F Ratios of Evaluation and Attraction (IJS) Scores for Three Levels of Judgmental Similarity

\begin{tabular}{|c|c|c|c|c|c|c|c|}
\hline \multirow[b]{3}{*}{ IJS Items } & \multicolumn{6}{|c|}{ Proportion of Similar Judgments } & \multirow{3}{*}{$\begin{array}{c}\mathbf{F} \\
\text { Ratio }\end{array}$} \\
\hline & \multicolumn{2}{|c|}{0} & \multicolumn{2}{|c|}{.50} & \multicolumn{2}{|c|}{1} & \\
\hline & M & SD & $\mathbf{M}$ & SD & $\mathbf{M}$ & SD & \\
\hline Intelligence & 4.12 & .88 & 4.50 & .89 & 5.35 & .79 & $9.05^{*}$ \\
\hline Knowledge & 3.88 & 1.02 & 3.75 & .97 & 4.76 & .90 & $5.78 *$ \\
\hline Morality & 4.12 & .88 & 4.75 & 1.07 & 4.70 & 1.21 & 1.80 \\
\hline Adjustment & 4.62 & .72 & 5.15 & .93 & 5.18 & 1.13 & 1.80 \\
\hline Liking & 4.12 & .81 & 4.65 & .99 & 5.76 & .75 & $15.68^{*}$ \\
\hline Working & 4.19 & .91 & 4.80 & .95 & 5.35 & .93 & $6.43^{*}$ \\
\hline Attraction Sum (5\& 8$)$ & 8.31 & 1.58 & 9.45 & 1.57 & 11.12 & 1.36 & $14.46^{*}$ \\
\hline Total & 25.06 & 3.06 & 27.60 & 3.65 & 31.12 & 2.74 & $14.92 *$ \\
\hline
\end{tabular}

$* p<.001$

plus questions on the S's liking for the other and his desire to work with the other in an experiment. (The first four items are considered measures of evaluation and the last items measures of attraction.) Actually, the answered questionnaire that the $S$ received was a fake one, made up by the $\mathrm{E}$, designed to agree or disagree with the one the $S$ had answered the week before.

The Ss had been divided randomly into three groups: one group received the information questionnaire with opposite answers (0\% agreement), another received the questionnaire with the same answers in half of the questions and different answers on the other half of the questions $(50 \%$ agreement), and the third group received the questionnaire with exactly the same answers on all the questions (100\% agreement).

\section{RESULTS AND DISCUSSION}

Analyses of variance of evaluative and attraction scores as functions of judgmental similarity-dissimilarity were computed. Table 1 shows the means, standard deviations, and $F$ ratios of scores on the IJS items for the three experimental groups. The effects of similarity on the attraction items (liking and working together), on the sum of the attraction items, and on the sum of all items (total-evaluative attraction) were stistically significant in the predicted direction. Also, significant differences in the expected direction were found on the evaluative items dealing with intelligence and knowledge, and a nonsignificant trend was found in the morality and adjustment items.

The results have demonstrated that attraction is functionally related to judgmental similarity under conditions of delayed information and in the absence of interpersonal interaction. Apparently, agreement in the more cognitive aspects of attitudes have effects similar to those of agreement in the more evaluative aspects of greement in the morne, 1969). It should be 